\title{
Management of Head Injury by General Surgeons in a General Hospital
}

\author{
Ghimire , $^{1^{*}}$ Yogi $N,{ }^{1}$ Acharya $\mathrm{GB}^{1}$
}

${ }^{1}$ Department of Surgery, Manipal Teaching Hospital, Pokhara, Nepal

\section{* Corresponding Author: \\ Dr. Pradeep Ghimire, MS, FRCS (Ed) \\ Department of Surgery \\ Manipal Teaching Hospital, Pokhara \\ Email: pradeepg757@hotmail.com}

\section{Citation}

Ghimire P, Yogi N, Acharya GB. Management of head injury by general surgeons in general hospital. Nepal Journal of Medical Sciences. 2012; 1(1): 19-22.

\begin{abstract}
Background: Head injury is one of the common causes of surgical admission in Western Regional Hospital, Pokhara, Nepal. With no neurosurgeons available, most of the cases are managed effectively with adequately trained general surgeons. The aim of the study is to study the epidemiology, incidence and pattern of head injury and their outcome in a setting of a general hospital where they were managed by general surgeons.
\end{abstract}

Methods: This is a prospective analytical study of 1847 head injury patients. The study defines the patterns of head injury, their management by general surgeons and outcome in surgery ward, Western Regional Hospital, Pokhara for about five years (1999 to 2003).

Results: Head injury comprised $15.5 \%$ (1847) of total admissions (11901) in surgery ward. Out of those, 80.5\% (1487) were mild, 10.4\% (192) moderate and $9 \%$ (168) severe head injury cases, based on Glasgow coma scale. Majority of cases (42.1\%) were young adults between $21-40$ years. $70 \%$ (1294) of cases were male and 30\% (553) were female. 7.5\% (138) cases were associated with skull fractures. Most of the cases showed good recovery. Only $2 \%$ required surgery; $3.7 \%$ were referred; $2.8 \%$ died and $0.8 \%$ left against advice.

Conclusion: Most of the cases of head injury can be managed by general surgeon in a General Hospital provided basic facilities like high dependency unit, Intensive care unit and a dedicated team are available.

Keywords: Glasgow Coma Scale; head injury; traumatic brain injury

\section{Background:}

Head injury is one of the common surgical condition which causes increased morbidity and mortality worldwide. ${ }^{1,2}$ It results from a number of factors including Road Traffic Accident (RTA), fall injury, physical assault etc. It is a source of major disability and huge financial and psychological burden upon society. Failure of adequate and timely managements results into a spectrum ranging from mild contusion to neurological deficit and death.

Head injury is one of the common causes of surgical

admission in Western Regional Hospital, Pokhara, Nepal. At the time of this study there were no neurosurgeons available at this region. At present though there is a neurosurgeon present, neurosurgical services are not fully available. Most of the cases have been managed quite effectively with few referrals and few deaths by adequately trained general surgeons in neurosurgery, anesthetists and nursing staffs together with computed tomography (CT) scan and resuscitation facilities.

The aim of the study is to study the epidemiology, incidence and pattern of head injury, and their outcome in a general 
hospital of western region of Nepal, where they were managed by general surgeons.

\section{Methods:}

This prospective analytical study was conducted during the period of 1999 to 2003 in Western Regional Hospital, Pokhara, Nepal in all the admitted cases of head injury $(n=$ 1847 ) in the surgical ward. After an initial examination and ressucitation in the emergency room, patients were categorized according to the Glasgow Coma Scale (GCS) into mild, moderate and severe head injury. A routine $\mathrm{X}$ ray of the skull was performed in all cases and a CT was ordered in cases that deteriorated during observation or those who presented with severe head injury. Patients were then managed according to the findings as guided by their clinical assessment, Skull X-ray and CT findings. Patients with mild head injury and without any features of raised Intracranial Pressure (ICP) or any further deterioration during their stay in emergency room were discharged with an advice slip, whereas those showing any features of raised ICP, deterioration in their GCS and also those coming from very distant area were admitted for observation. All cases of moderate and severe head injury were admitted. Decision to operate or refer was taken on the basis of patient's clinical condition and CT findings.

Data was collected in a preformed Performa and analyzed in the form of age and sex distribution, mode of injury, severity of head injury and pattern of management.

\section{Results:}

Head injury comprised of $15.5 \%$ (1847) of total admissions (11901) in surgery ward during the period of this study. Their age ranged from 1-86 years with a mean age of 30.23 years. Majority of the patients were young adults between 21-40 years of age (Table 1 ).

Table 1: Age distribution

\begin{tabular}{lcc}
\hline Age Group (Years) & Frequency & Percentage \\
\hline $0-20$ & 520 & $28.1 \%$ \\
$21-40$ & 778 & $42.1 \%$ \\
$41-60$ & 296 & $16 \%$ \\
$61-80$ & 132 & $7.1 \%$ \\
$81-100$ & 111 & $6 \%$ \\
\hline
\end{tabular}

$70 \%$ (1294) of cases were male and 30\% (553) were female. Out of these, $80.5 \%$ (1487) had mild, 10.4\% (192) moderate and $9 \%(168)$ severe head injury based on Glasgow coma scale (Table 2).

Table 2: Severity of Head Injury

\begin{tabular}{lcc}
\hline $\begin{array}{c}\text { Severity of } \\
\text { Head Injury }\end{array}$ & $\begin{array}{c}\text { Number of } \\
\text { Patients }\end{array}$ & Percentage \\
\hline Mild & 1487 & $80.5 \%$ \\
Moderate & 192 & $10.4 \%$ \\
Severe & 168 & $9 \%$ \\
\hline
\end{tabular}

Fall from height (45\%) and RTA (44\%) were the leading causes of head injury at this region. X-ray skull was done in all cases and showed fracture in 138 cases (7.5\%). CT head was done in 232 cases (12.5\%). Most of these cases were moderate and severe head injuries. Contusion (48.2\%) followed by $\mathrm{EDH}(33.1 \%)$ and $\mathrm{SAH}(28.8 \%)$ were the commonest lesions (Table 3).

\section{Table 3: Findings on CT scan head}

\begin{tabular}{lcc}
\hline CT Findings & Frequency & Percentage \\
\hline EDH & 77 & $33.1 \%$ \\
SDH & 21 & $9 \%$ \\
Contusion & 112 & $48.2 \%$ \\
SAH & 67 & $26.8 \%$ \\
Fracture & 43 & $18.5 \%$ \\
Pneumocephalus & 28 & $12 \%$ \\
Normal Scan & 22 & $9.4 \%$ \\
\hline
\end{tabular}

Most of the cases were treated conservatively and surgery (craniotomy) was done in 37 patients (2\%). 3.7\% (69) patients were referred to higher centers, $2.8 \%$ (52) cases died during the course of treatment \& $0.8 \%$ (16) cases left against medical advice (Table 4).

Table 4: Management pattern of patients

\begin{tabular}{lcc}
\hline Management Pattern & Number & Percentage \\
\hline Conservative & 1673 & $90.5 \%$ \\
Surgery & 37 & $2 \%$ \\
Referral & 69 & $3.7 \%$ \\
Left Against Advice & 16 & $0.8 \%$ \\
Death & 52 & $2.8 \%$ \\
\hline
\end{tabular}




\section{Discussion:}

Most of the cases $(42.1 \%)$ in our study were young adults from 21-40 years old. Also the incidence was found higher in males $(70 \%)$ than in females $(30 \%)$. Most common causes of head injury were fall from height (45\%) and RTA (44\%). These findings are similar to the studies conducted in various parts of Nepal and elsewhere..$^{3-5}$ Fall is common in this part of the country because of is geographical terrain consisting of mainly hills and mountains whereas RTA is attributed to reckless and uncontrolled driving specially in the young adults and also at times under the influence of alcohol.

There were $80.5 \%$ of mild head injury, $10.4 \%$ of moderate and $9 \%$ of severe head injury in this study. In literatures all around, mild head injury (60-90\%) comprises the majority of all head injuries whereas moderate (10-30\%) and severe head injuries $(5-15 \%)$ are very minimal. ${ }^{3,5-7}$

Though CT is the first line investigation to detect immediately life threatening lesions and MRI is the examination of choice for full assessment of brain lesions ${ }^{8}$ these investigation modalities are rarely available all throughout in a developing country like Nepal. In our case we had a CT scan service being availed by the private sector which was used in the required cases if afforded by the patients. X-ray of the Skull was taken routinely. However X-ray cannot demonstrate the routine intracranial injury. ${ }^{3,9}$

Neurosurgery is currently in a blooming phase in Nepal. During the $1^{\text {st }}$ year of establishment of neurosurgical unit in Bir hospital in Kathmandu, Nepal; 34 cases of head injury were admitted $\&$ treated. The addition of modern neurodiagnostic aids \& neurosurgical instruments greatly improved the quality of neurosurgical work in Nepal. ${ }^{10}$ From a stage where there was just a single neurosurgeon in $1989,{ }^{11}$ Nepal has traveled a long way to the present situation where there are more than 11 neurosurgeons at present. Though the number is increasing, most of them are working in the capital city leaving behind the remaining part of Nepal in its previous state. In such condition the burden of treatment and care of neuro-trauma has to be taken by the general surgeons and the results are nowhere lesser if these general surgeons are adequately trained in handling neuro-trauma. In our study, there was only $2.8 \%$ mortality and $3.7 \%$ referral. Most of the cases showed good recovery at discharge.

Management of the traumatic brain injury in a nonneurological referral center is basically designed to prevent secondary brain injury and also to provide the neurosurgeon with a live patient who has some hope of recovery at referral. ${ }^{12}$ Current therapeutic approaches aim to reduce mortality and improve patient outcome, of which the associated disability has significant functional, social and economic sequel. The mechanical deformation of the brain that occurs at the moment of impact in severe head injury leads to both focal injury (contusions and cortical lacerations) and diffuse axonal injury, both of which are described as the "primary brain injury". Brain damage does not cease with the impact but progresses over subsequent hours and days ("secondary brain injury"). Secondary injury may be due to intracranial causes, such as surgical mass lesions, focal or global brain swelling causing elevated intracranial pressure and seizures, and extra cranial causes, such as hypotension, hypoxia, hyper/hypocarbia, hyper/hypoglycemia, anemia, pyrexia, electrolyte abnormalities, coagulopathies and infection. On a cellular level these insults lead to amino acid excitotoxicity, free radical damage, lipid peroxidation, calcium-mediated damage, neuron-inflammation, ischemia and neuronal death. There is currently no treatment for primary brain injury, so the mainstay of management of moderate or severely head injured patients rests on the prevention and treatment of secondary brain damage. ${ }^{13}$

\section{Conclusion:}

Fall from height and RTA were the main cause of head injury in western region of Nepal. Young adults and males were the common ones affected.

More than $80 \%$ cases were mild head injury managed successfully in the general hospital. Very few $(2 \%)$ required operative treatment and only $3.7 \%$ were referred. Most of the cases showed good recovery at discharge. There was only $2.8 \%$ mortality. This suggests that in absence of a neurosurgeon, General surgeons who are adequately trained in neuro trauma can manage most of the cases with favorable results.

\section{References:}

1. Kay A, Teasdale G. Head injury in the United Kingdom. World J Surg 2001; 25: 1210-20.

2. Sanchez JI, Paidas CN. Childhood trauma. Now and in the new millennium. Surg Clin North Am 1999; 79: 1503-35.

3. Agrawal A, Agrawal CS, Kumar A, et al. Head injury at a tertiary referral centre in the Eastern Region of Nepal. East and Central African Journal of Surgery 2009; 14: 57-63. 
Original Article | Ghimire P, et al. Management of head injury by general surgeons.

4. Gururaj G, Kolluri S. Problems and determinants of traumatic brain injuries in India. NIMHANS J 1999; 17:407-22.

5. Eguare E, Tierney S, Barry MC, et al. Management of head injury in a regional hospital. IrJ Med Science 2000;169:228.

6. Kraus JF, Black MA, Hessol N, et al. The incidence of acute brain injury and serious impairment in a defined population. Am J Epidemiology 1984;119:186-201.

7. Annegers JF, Grabow JD, Kurland LT, et al. The incidence causes and secular trends of head trauma in Olmsted County, Minnesota, 1935-1974. Neurology 1980;30:912-9.

8. Braun M, Cordoliani YS, Dosch JC. Head and brain injuries. Place of imaging. Ann Fr Anesth Reanim 2000;19:296-8.
9. Simon SD, Dodds RD. The use of skull X-rays in the accident and emergency department. Ann R Coll Surg Engl 2003;85:120-2.

10. Devkota UP. Neurosurgery unit celebrates its first anniversary. J Nep Mep Med Assoc 1982;20:35-7.

11. Sakowitz OW, Sharma MR, Kiening KL et al. Current concepts in diagnosis and treatment of traumatic brain injury: Implication for healthcare in Nepal. Nepal $\mathbf{J}$ Neurosci 2005;2:29-51.

13. Winter CD, Adamides AA, Lewis PM et al. A Review of the current management of severe traumatic brain injury. The Surgeon 2005;3:329-37.

14. Flannery T, Buxton N. Modern management of head injuries. J Roy Coll Surg Edinburgh 2001;46:150-3. 